\title{
Brand clarity of local and global brands in fast-moving consumer goods: an empirical study in a Middle East country
}

\author{
Maryam Vaziri \\ Department of Business, Autonomous University of Barcelona, Bellaterra, Spain, and \\ Joan Llonch-Andreu and Pilar López-Belbeze \\ Department of Business, Universitat Autònoma de Barcelona, Barcelona, Spain
}

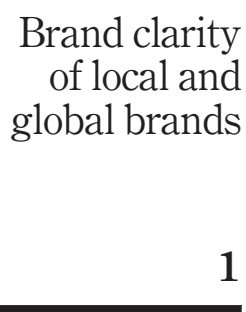

Received 18 January 2020

Revised 22 August 2020

24 October 2020

16 March 2021

Accepted 16 June 2021

\begin{abstract}
Purpose - This paper aims to analyze different brand clarity levels (BCLs) of local, global and glocal types of brands in fast-moving consumer goods from the consumer's perspective. The study also intends to identify whether the consumer's previous experience with such brands may impact BCL.

Design/methodology/approach - Twenty-eight global and local brands were used to test the hypotheses by conducting a survey with 400 consumers in the emerging economy of Iran. The authors applied a quantitative technique of brand classification, previously proposed in the literature. After categorizing the brands as local, global or glocal, one-way ANOVA, Tukey post hoc and t-test analyses were performed to identify whether the different types of brands had different BCLs.

Findings - The results showed that brand clarity was significantly higher for local bands than for global or glocal brands and that it was higher for glocal bands than for global brands. Furthermore, the consumer's prior experience with a brand had no impact on BCL for different types of brands.

Social implications - For global brand managers, it is essential to know that local brands in Middle Eastern emerging markets may have more brand clarity than global brands. Therefore, if global brands intend to enter these markets, adopting a glocal positioning appears to be a helpful strategy. Besides, the results suggest that managers should analyze brand categorization from the consumer's perspective, i.e. from a subjective instead of an objective perspective.
\end{abstract}

Originality/value - This was the first study analyzing the BCL of local, global and glocal brands and identifying significant differences in their BCL.

Keywords Emerging economy, Global brand, Glocal brand, Local brand, Brand clarity

Paper type Research paper

\section{Introduction}

The cultural dimension of globalization is an exchange in cultural behavior and values through business, migration, media, technology, etc. Cultural globalization opens various gates to the unfamiliar and dissimilar cultural icons (Ozer, 2019). Individuals in the current globalized societies need to negotiate with multiple flows of foreign cultural streams (Ozer, 2019).

(C) Maryam Vaziri, Joan Llonch-Andreu and Pilar López-Belbeze. Published by Emerald Publishing Limited. This article is published under the Creative Commons Attribution (CC BY 4.0) licence. Anyone may reproduce, distribute, translate and create derivative works of this article (for both commercial and non-commercial purposes), subject to full attribution to the original publication and authors. The full terms of this licence may be seen at http://creativecommons.org/licences/by/4.0/legalcode

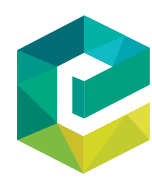

Journal of Islamic Marketing Vol. 14 No. 1,2023 pp. $1-22$ Emerald Publishing Limited 1759-0833 DOI 10.1108/JIMA-01-2020-0018 
JIMA 14,1

Contemporary consumer markets in Asia and the Middle East are globalizing and transforming with high acceleration (Cavusgil et al., 2018; Potrafke, 2015). On the other side, consumer behavior and preferences in Muslim countries are formed culturally because of the particular religious effect in food industries (Muhamad and Mizerski, 2010). There is still a gap for brand managers about Muslim consumer's preferences based on their emotions and brand messages (Wilson and Liu, 2011).

The current consumer market for local and global brands is changing due to developments in globalization processes (Sichtmann et al., 2019). Therefore, the global consumer culture (GCC) may change in the future (Steenkamp, 2019). Global brands have the advantage of universal accessibility (Davvetas et al., 2015), whereas local brands have a responsive, localized preference among consumers (Schuiling and Kapferer, 2004). So-called glocal brands combine global and local features (Khondker, 2004; Dumitrescu and Vinerean, 2010). Brands simultaneously can be perceived global and local (Steenkamp et al., 2003; Winit et al., 2014), and firms attempt to influence consumer's brand perception by establishing effective global, local and glocal marketing strategies through signals (Keller and Lehmann, 2006; Dumitrescu and Vinerean, 2010; Yakup and Diyarbakirlioglu, 2011). A brand signal can be a tangible sign such as touch, sight and sound, which can be received, stored and recalled by the brain's neurobiological systems (Erdem and Swait, 1998).

Furthermore, brands can create a special relationship with consumers' minds through brand personality, brand ambassadors and brand sponsorships. Brand perception is influenced by the consumer's personal and cultural aspects, both relational and emotional (Aaker et al., 2004; Thomson et al., 2005; Kervyn et al., 2012). The consumer's interpretation of a brand can be influenced by local customs and symbols such as colors, persons, manners and habits (Kushwah et al., 2019). The perception process is affected by the physical characteristics of a brand, as presented by companies, and individual characteristics of consumers (Hanna and Wozniak, 2013). The discipline of consumer behavior helps to understand what consumers think and perceive of brands, products and companies (Peter et al., 1999). Understanding the dynamics behind the consumer's selection process for local and global brands is an important issue for marketers and academics (Schuiling and Kapferer, 2004; Veloutsou, 2008; Özsomer, 2012; Steenkamp, 2017). However, more research is required to identify how local and global cultural factors and brand symbolism can influence consumers' consumption patterns.

According to the signaling theory, product position is created by advertising signals (Kirmani, 1990), product quality and brand name signals (Davis and Rao, 1991), affecting consumers' perception. Erdem and Swait (1998) developed the signaling theory, stating that brands were a source of information for consumers and that key signals were brand clarity and brand credibility. The theory says that a high level of ambiguity and complexity in brand signals leads to a lower level of clarity in the consumer's mind. However, little is known about the brand clarity of local, global and glocal brands. Thus, this study made a significant contribution to the literature on the signaling theory by analyzing whether there were substantial differences in the brand clarity level (BCL) depending on the type of brand (local, global or glocal).

Based on this theory, consumers with low prior experience with a brand will rely mainly on user-image cues when forming their attitude toward a brand identity. Conversely, consumers with high prior experience with a brand, i.e. consumers who have used the brand, assign a higher BCL to a brand compared to those who have never tried it because of less ambiguity, information cost and perceived risk they assign to the brand (Erdem and Swait, 1998). Thus, the brand clarity (BCL) of different types of brands is expected to be influenced by the consumer's previous experience with those brands (PEB). 
Although global and local brands employ global and local iconic brand positioning strategies through their privileges and impediments (Heinberg et al., 2017), the logical way to classify brands should be based on the consumer's perspective (Halkias et al., 2016); however, consumer-based brand categorization $(\mathrm{CBBC})$ has not been given much attention. Recently, some researchers have developed a quantitative method to categorize brands from the consumer's perspective into local, global and glocal brands. The method has been empirically tested in the emerging economy of Mexico (Llonch-Andreu et al., 2016). This method is based on the categorization of attitudes toward local and global products previously introduced by Steenkamp and De Jong (2010). Llonch-Andreu et al. (2016) suggest that brand categorization based on the consumer's perspective (a subjective approach) might differ from the traditional (objective) brand categorization criterion. The study's central research question is to identify the level of brand clarity and brand experience of different types of brands based on the new brand categorization method from the consumer's point of view.

Hence, our research objectives are summarized as follows:

- To determine whether there are significant variations in the BCL between local, global and glocal brands for fast-moving consumer goods (FMCG).

- To understand whether the consumer's previous experience with a brand (PEB) can affect the BCL of different types of brands.

The data for this research were gathered with a survey in an emerging economy and Muslim in the Middle East. New emerging markets with a considerable number of consumers need to be empirically studied in the domain of local and global brands (Erdem et al., 2006; Llonch-Andreu et al., 2016; He and Wang, 2017). Further, most of the Muslim population has 4.19\% of the total world GDP (Thomson Reuters, 2016). This study considered Iran as a Muslim particular and less discovered market with a high potential to explain different perspectives, different consumption patterns and attitudes. It will be thought-provoking to compare the consumer's attitudes in emerging markets with those in developed economies (He and Wang, 2017). Thus, the researchers are encouraged to pay more attention and do more research in Muslim regions to publish in top-ranked journals like JIMA (Floren et al., 2019).

\section{Literature review}

According to Kotler (2009), global brands' marketing strategies connect to maximize standardization and consistency in marketing activities across global markets, while local brand's marketing strategies relate to consumers' unique needs and adaptation of the marketing activities in individual counties. Several studies have revealed that consumers' personal and cultural aspects influence their brand perception, both relationally and emotionally (Aaker et al., 2004; Thomson et al., 2005; Kervyn et al., 2012). Besides, by growing Muslim population and demographic changes, Islamic markets and halal products are going to be more attractive for international companies, whereas the well-known global brands such as Colgate, Nestle, Loreal and Unilever are very familiar and developed in Islamic Markets (Ogilvy Noor, 2010; Izberk-Bilgin and Nakata, 2016; Floren et al., 2019). Global and local brands have connected to global and local iconic brand positioning through their privileges and impediments (Heinberg et al., 2017). From a traditional point of view, the brand categorization concept has concentrated on two brand categories of local and global and explains that local or global brand positioning leads to the company's sales and revenue (Özsomer and Altaras, 2008; Schuiling and Kapferer, 2004; Llonch-Andreu et al., 2016). This study reviews the existing literature on types of brands according to consumer's perception and brand clarity as a driver in signaling theory. 
JIMA

14,1

\subsection{Types of brands (local, global and glocal)}

Local brands are considered available in a limited geographical region or a concentrated market (Dimofte et al., 2008; Schuiling and Kapferer, 2004). Consumers may perceive brands as local if they tie with local culture, apply local symbols and themes or fit unique local necessities (Alden et al., 2006; Steenkamp, 2017; Llonch-Andreu et al., 2016). Signals of uniqueness, market availability, originality and higher awareness represent local brand icons (Özsomer, 2012). A local brand preference can be found in the consumer's nationalistic feeling as a social factor (Kapferer, 2002). Schuiling and Kapferer (2004) found more price flexibility for local brands in a cross-country study than for global brands in fast-moving consumer goods. Moreover, local brands have a powerful position to better respond to regional needs, prevent the market entry of global brands, and ultimately increase economic growth (Schuiling and Kapferer, 2004; Godey and Lai, 2011).

According to Özsomer and Altaras (2008), global brands are defined as global awareness and availability. They are often found under the same name with consistent positioning, image, personality, look and feel in major markets. They are enabled by standardized and centrally coordinated marketing strategies and programs (p. 1). Global brands are looking for international presence by observing the highest standardization; for example, by using unique brand name, unique or global brand positioning and marketing mix (Godey and Lai, 2011). Consumers may perceive brands as global if the brands underline global symbols or foreign words.

However, Godey and Lai (2011) defined a glocal brand as a local brand according to global positioning. They mentioned that glocal brands could be categorized as local brands, which had been expanded with unique brand positioning (Godey and Lai, 2011). A broader perspective argues that consumers perceive brands as glocal when they receive a global quality with a local touch or when they perceive brands use an integral local and global icons or a combination of foreign and local words (Alden et al., 2006; Steenkamp, 2017; Llonch-Andreu et al., 2016). Glocal brands are difficult to perceive because they are consequences of the blended brand positioning approach (Baker et al., 2007). Some global brands are adapted to local markets, and some other local brands are adjusted to global markets. At the same time, consumers can perceive glocal brands through the combination of global and local icons, which are the outcomes of the company's marketing mix strategies (Llonch-Andreu et al., 2016). For glocal brands, there is an integral mix of local and global elements (Alden et al., 2006; Llonch-Andreu et al., 2016), and thus, the "glocalization" strategy appears (Giulianotti and Robertson, 2012).

Maynard and Tian (2004) defined glocalization as "the process of global corporations tailor products and marketing to particular local circumstances to meet variations in consumer demand" (p. 6). This definition is complemented by Dumitrescu and Vinerean (2010), claiming that glocalization was "providing a global offer (brand, idea, product, service, etc.), while taking local related issues into account." Glocal brands with lower costs can respond to local preferences along the company's global margin; therefore, they can compete better than local and global brands in both markets (Dumitrescu and Vinerean, 2010). Glocal brand positioning is a strategic effort to balance local customization and global homogenization (Svensson, 2001). It can also be an interaction between localization and globalization vectors to provide a reputation for a global brand by maintaining its public image in the local market (Maynard and Tian, 2004). Robertson (1992) points out that glocalization can touch a broader range of consumers by creating a balance between universal and particular cultures. In the context of local and global brand positioning, companies attempt to impress consumers' perceptions by using effective marketing strategies (Yakup and Diyarbakirlioglu, 2011; Keller and Lehmann, 2006). Brand 
localization, globalization and glocalization positioning need to be considered in countries with emerging or developed status (Sichtmann et al., 2019).

Steenkamp and De Jong (2010) carried out some investigations about consumers' attitudes toward global and local products. This study attempts to determine what motivational structures are provided by attitude toward global products (AGPs) and attitude toward local products (ALPs). They realized that people highly interested in creativity for local and global products preferred response glocalization or hybrid responses. This was primarily assigned to forward-looking women and value materialism. Localization responses were produced by older people with more traditional value intention who preferred local products. Homogenization responses were given to younger and highly stimulated people with more utility for global products. Finally, people consuming products in general who were less motivated in local and global brands were assigned to the glalienation response category (Steenkamp and De Jong, 2010).

In the same vein, Halkias et al. (2016), in their study, argued that whether brand globalness or localness, country stereotype, and country's specific factors were related to the prediction of brand preference. This study presented some evidence to elaborate that local and global brand positioning and brand association by the country of origin effectively established a brand value (Halkias et al., 2016). Drawing on the concept of local and global brand categorization, Llonch-Andreu et al. (2016) developed a new methodology to compare consumer and non-consumer approaches for brand categorization. They found that there was a moderate agreement between the traditional (objective) brand categorization and the consumer's perception of brand categorization from two dimensions, perceived brand globalness (PBG) and perceived brand localness (PBL). In the current study, the authors applied a methodology proposed by Llonch-Andreu et al. (2016) to classify brands into local, global and glocal from a consumer's perspective in another emerging market.

\subsection{Brand clarity in the signaling theory}

Erdem and Swait (1998) believe that brands as market signals can increase brand claim confidence and improve consumers' perception of brands. The signaling phenomenon's conceptual framework explains that clarity and credibility are the brand signal's main characteristics (Erdem and Swait, 1998). The signaling theory states that brand clarity is the absence of information ambiguity and activities associated with marketing mix strategies of brands and that the perceived quality influences consumer expected utility, saved information cost and reduced perceived risk (Erdem et al., 2006).

Moreover, the clarity of a brand is linked to whether consumers perceive marketing mix strategies of companies understandable or rather vague to understand. Brand clarity is related to the degree of vagueness that consumers can perceive from a brand in companies' information (Erdem and Swait, 1998). Two indicators explain brand clarity: whether the consumer knows what a brand stands for and whether the consumer has trouble figuring out what image the brand is attempting to create (Erdem and Swait, 1998). Erdem and Swait (2004) conducted another research to analyze the role of brand credibility elements (trustworthiness and expertise) in considering and choosing brands in different product categories. Their results showed that trustworthiness had a higher impact than expertise on the consumer's choice and brand consideration. However, they did not analyze brand clarity. In the same vein, brand credibility, as the central construct of brand equity, impacts the consumer's choice in all sample countries (Erdem et al., 2006); however, brand clarity was considered in none of the countries. 
JIMA 14,1

Furthermore, when brand signals are more transparent and more consistent, consumers perceive them to be more trustable with higher quality. Consistency and clarity together as brand signals increase consumer purchase intention through higher perceived quality (Erdem and Swait, 1998). More recently, Lopez-Lomelí et al. (2019) attempted to identify the indirect effect of types of brands on consumer purchase behavior through signaling components. They showed that types of brands (local, global and glocal) could moderate the relationship in the belief-attitude-purchase intention model. It also explains that consumers have more problems positioning glocal brands due to their ambiguity, making them less clear and credible.

According to the signaling theory (Erdem and Swait, 1998), brand clarity positively affects perceived quality, although this effect is stronger for perceived risk. Previous studies demonstrated that the consumer's higher PBG was related to the consumer's higher perceived quality (PQ) (Batra et al., 2000; Steenkamp et al., 2003; Alden et al., 2006; Özsomer, 2012). However, Özsomer (2012) showed that PBL was positively related to perceived quality for food categories in local brands, whereas PBL was not related to perceived quality in non-food categories. It means that the relationship between perceived brand localness and perceived quality varied across product categories. Thus, when consumers fully receive globalness (localness) signals from global (local) brands separately, it is expected that they perceive a higher BCL for those brands.

Glocal brands result from a high-perceived brand localness and high-perceived brand globalness from the consumer's perspective (Llonch-Andreu et al., 2016). Therefore, it is a widely held view that glocal brands are more ambiguous through received information by their past and present marketing mix and social activities (Lopez-Lomeli et al., 2019). When consumers perceive a high level of both PBG and PBL, a brand can be considered glocal (Llonch-Andreu et al., 2016). However, based on the signaling theory, consumers may have more problems positioning glocal brands because of their ambiguity, making them less clear (Erdem and Swait, 1998; Erdem et al., 2006; Lopez-Lomelí et al., 2019). Thus, it is expected that glocal brands have a lower BCL compared with local or global brands. When consumers receive both globalness and localness signals simultaneously from a brand, it is expected that they perceive a lower BCL for those brands due to indefiniteness in types of brands. In other words, compared to global and local brands, consumers may perceive a higher risk for glocal brands because of their lower BCL, which is attempted to be justified in the current study. Therefore, our first hypothesis is as follows:

H1. The brand clarity level is lower in glocal brands than in local and global brands.

However, prior experience with a brand has a positive impact on brand trust through brand satisfaction. Therefore, it is logical that consumers can trust some brands and be attracted (Chinomona, 2013). The importance of consumer's previous experience with those brands (PEB) becomes visible through attitudes toward brands that appeared in consumers' first purchase. According to the literature, attitudes are more likely to be influenced by utilitarian cues (such as product design or product performance) for consumers with high prior experience with a brand and by user-image based signals (such as brand name and country of origin) for consumers with low prior experience (Mangleburg et al., 1998; Wood and Kallgren, 1988). Therefore, when consumers with low previous experience form their attitudes toward brands, they will trust user-image indicators. Brand identity from local/ global images is a user-image indicator. Thus, consumers who have tried specific brands are expected to have a higher BCL than those who have never tried them because they assign less ambiguity to those brands (Erdem and Swait, 1998). 
Hence, our second hypothesis is as follows:

H2. The brand clarity level is lower in glocal brands than in local or global brands among consumers with no prior experience of those brands.

\section{Methodology}

3.1 Data collection and sample

An emerging Muslim market was selected for this research because of its different demographic, social and cultural characteristics. Countries with an emerging economy have the fastest and youngest growing population globally than more developed and Western countries (Murray, 2018). These markets are trying to improve their competitiveness by developing their local brands through innovative marketing strategies and create long-term images (Chailan and Ille, 2015). Tehran has been selected for a couple of reasons, as this city is the capital and most populous city in Iran, with a population of 9,013,663 (Tehran Population, 2019). Tehran is the center of international brands with many upper- and middle-class shops, internationally branded stores and retail stores, including local and global brands (City mayors, 2017). Another reason for selecting Tehran was that the city had been considered the destination for the people's mass migration from all around Iran in the 20th and 21st centuries (World Capital Institute, 2013). Thus, Tehran can be a mirror and representative sample of Iran due to its ethnic, cultural diversity and large urban population regarding consumption patterns for local and global brands (World Capital Institute, 2013).

This study applied the probabilistic sampling method (Sekaran, 1983) to randomly select samples representing the entire Iranian Muslim population. We used stratified random sampling to divide a more extensive population into smaller groups arranged with age and gender percentage in national population segmentation (Neyman, 1992). Participants of these groups are distinct, and all group members receive an equal opportunity to be chosen by using simple probability. A survey was conducted with 400 participants via face-to-face interviews during January and February 2017. The authors applied Krejcie and Morgan (1970) method to calculate the sample size based on population enhances, where the sample size increases at a reducing rate. Thus, the study was conducted with more than 380 cases, which were 400 participants. The paper-and-pencil personal interview (face-to-face interview) has been applied to enhance data collection quality, clarity and reduce the number of nonresponses (Lavrakas, 2008; Llonch-Andreu et al., 2016). This study was conducted in collaboration with an expert assistant in marketing research, and we considered adulthood as the age above 18 years old. Each participant completed a questionnaire including items on background demographics such as age, gender and educational level (Table 1).

\subsection{Data collection and brand}

Twenty-eight brands were selected from fast-moving consumer goods in two categories of food and personal care. Mass-produced, inexpensive daily products were chosen (olive oil, shampoo, hand soap, chocolate, toothpaste and tea) due to their short decision-making process, low purchase risk importance and low consumer involvement (Vera and Trujillo, 2017). Out of the 28 FMCG brands, 11 were global, and the remaining 17 bands were local. The global brands were considered their sales coming from outside the home region and in the top 100 list of Interbrand (2016) by presenting a clear image of brands referring to business growth, brand strategy, brand evaluation and positioning. According to Interbrand (the world's leading brand consultancy), global brands are defined to conduct at least onethird of sales as export from their home country and their customer's global awareness. The 


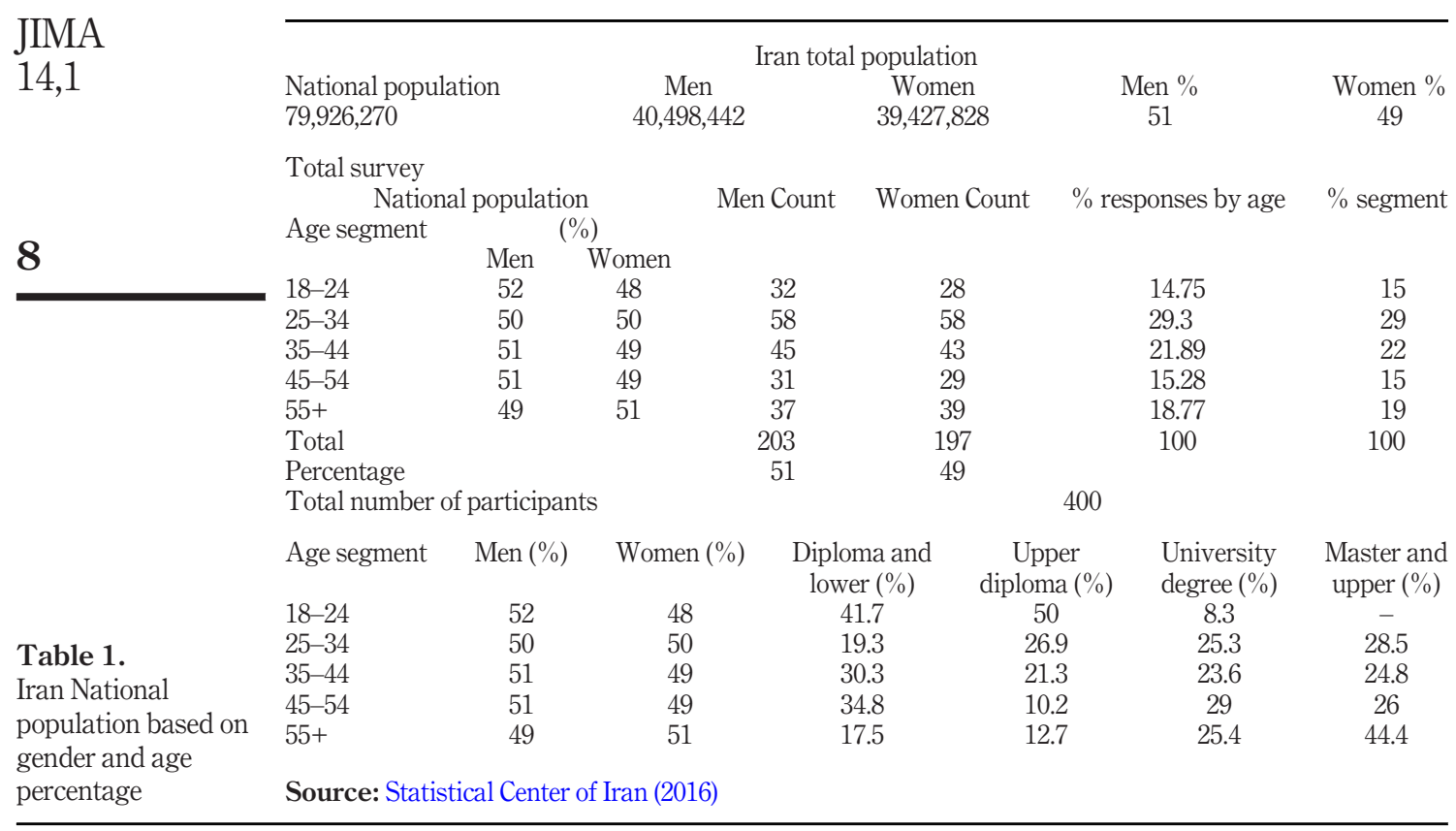

selected global brands were also checked with other various sources (Ranking the Brands, Ranker, Trending Topmost and Forbes) to rate the global brands according to their consumption patterns. The selected local brands were produced, sold and developed in a limited geographical area for the local consumer's unique needs (Özsomer, 2012).

Both local and global brands were selected based on their high brand familiarity among consumers. We used 28 brands across seven product categories; each category consisted of a mix of four local/global brands. The product categories were rotated across four sets of questionnaires (100 participants for each set) because of space, time limitations and to provide counterbalancing (Batra et al., 2000). As a result, each of the 400 participants was exposed to the questions about seven local and global brands. The researchers ended up with 100 completed and usable data for each set of participating brands (Llonch-Andreu et al., 2016) (Table 2).

Before the final survey, a pretest was conducted with a small sample to guarantee the readability and understandability of questions and brands in the questionnaire.

A questionnaire was developed to classify the brands into local, global and glocal from the consumer's point of view, following the categorization technique proposed by LlonchAndreu et al. (2016) through assessing PBG and PBL for each brand (Steenkamp et al., 2003). For all the questions, the study used a seven-point Likert scale ranging from 1 (strongly disagree) to 7 (strongly agree) to measure PBG, PBL and BCL. According to the psychometric literature, the seven-point Likert scale was applied because having seven points is the right balance between having enough discrimination issues and keeping excessive response options (Nunnally and Bernstein, 1994). For a previous experience with the brand (PEB), the consumers were asked whether they either used (yes) or did not use (no) a brand (Mangleburg et al., 1998; Wood and Kallgren, 1988). 


\section{Measures and measurement}

PBG and PBL were assessed through three dimensions for each adopted from Steenkamp et al. (2003). This study measured BCL by a scale with two items proposed by Erdem and Swait (1998) (Table 3).

To ensure that all measurement items were translated free of linguistic confounds, the questionnaire used in Iran was translated from English to Persian in a tripartite process. Also, to reaffirm that the translation was understandable and consistent with the scale items (Kotabe and Helsen, 2000), the back-translation process was performed. The back-translated English version of the questionnaire matched the original English version. A professional translator (the third party) who was not aware of the purpose of this research was hired to compare the original English and back-translated English versions of the questionnaire. Based on the suggestions of the translator, we made minor modifications to the Persian version in the main study. The respondents answered questions covering brand clarity, perceived brand globalness, perceived brand localness and prior experience with a brand.

To classify the brands according to this methodology, if the median of PBG is high (greater than 4 out of 7 in a seven-point Likert scale) and PBL is low (lower than 4 out of 7 in a seven-point Likert scale), it is considered a "global" brand; if the median of PBG is low and PBL is high in the scale, it is regarded as a "local" brand; if the median of PBG and PBL are both high in the scale, it is considered a "glocal" brand; and if the median of both PBG and PBL for a brand is low in the scale, it is regarded as a "functional" brand (Llonch-Andreu et al., 2016; Steenkamp and De Jong, 2010) (Figure 1).

\subsection{Construct reliability and validity}

By conducting 400 questionnaires, four sets of questionnaires, each set includes 100 participants, and each participant is asked about seven brands (see Table 2); the survey obtained 2,800 observations from 28 participating brands. For measuring, scales validity and reliability, exploratory factor analysis, convergent validity and discriminant validity have been conducted, and all of them got acceptable results based on the previous literature.

The composite reliability (CR) coefficients are greater than 0.70 and AVE greater than 0.50 for all constructs and obtain the recommended threshold of 0.70 (Nunnally and Bernstein, 1994), indicating appropriate reliability. The result for AVE, composite reliability $\mathrm{CR}$ and extracted variance EV suggest adequate convergence in all constructs. Tables 6 shows the reliabilities (CR), average variances extracted (AVE) and Cronbach's alpha (C $\alpha$ ) for total observations. All items loaded on the appropriate factors were significant and positive, standardized factor loadings were all greater than 0.7 in exploratory factor analysis (EFA). Besides, the reliability test for the three scales is supported by Cronbach's alpha due to all values above 0.7, indicating acceptable reliability (Churchill, 1979) (Table 4).

Furthermore, the study evaluates discriminant validity to present the distinctness of a construct when the square root of AVE for each latent variable is higher than other correlation values among any other construct (Fornell and Larcker, 1981). The mean values, standard deviations and correlations are reported in Table 5. It shows the adequate discriminant validity (bold on diagonal) has been achieved by the squared roots of the AVEs that were higher than the off-diagonal correlations (Table 5).

As the further measures of discriminant validity, Heterotrait-Monotrait Ratio (HTMT) (Henseler et al., 2015) and cross-loading for confirmatory factor analysis were assessed, and this study does not show discriminant validity problems for the observed and latent variables (Tables 6 and 7). 
JIMA

14,1

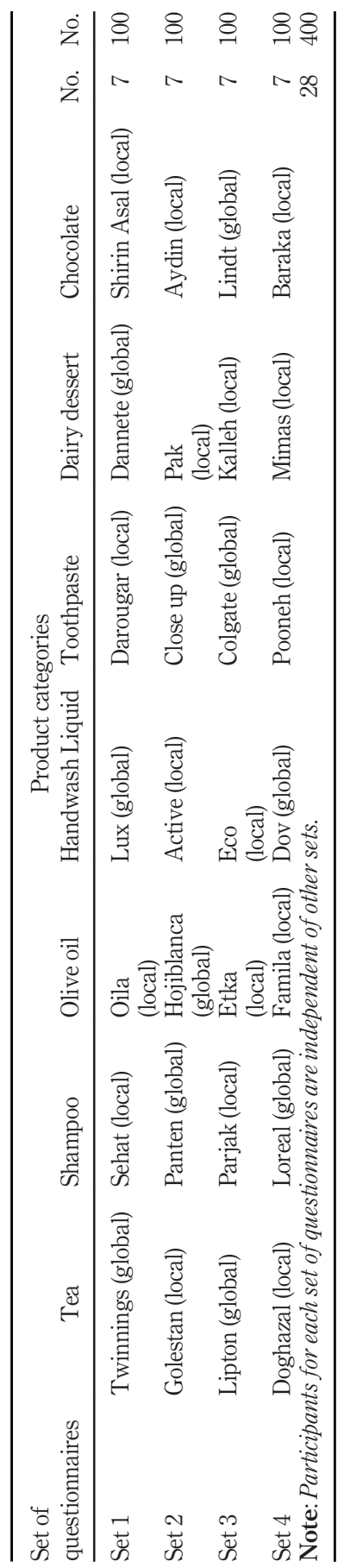

Table 2.

Brand data collection process 


\begin{tabular}{|c|c|c|c|}
\hline Scale & Measure & Source & $\begin{array}{l}\text { Brand clarity } \\
\text { of local and }\end{array}$ \\
\hline $\begin{array}{l}\text { Brand clarity } \\
\text { (BC) }\end{array}$ & $\begin{array}{l}\text { I know what this brand stands for } \\
\text { I have trouble figuring out what image this brand is } \\
\text { trying to create }(\mathrm{R})\end{array}$ & Erdem and Swait (1998) & global brands \\
\hline $\begin{array}{l}\text { Perceived brand } \\
\text { globalness (PBG) }\end{array}$ & $\begin{array}{l}\text { I think this is a Global brand } \\
\text { I believe that consumers from other countries buy this } \\
\text { brand } \\
\text { This brand is only sold in Iran }(\mathrm{R})\end{array}$ & Batra et al. (2000) & 11 \\
\hline $\begin{array}{l}\text { Perceived brand } \\
\text { localness (PBL) } \\
\text { Note: } \mathrm{R} \text { = Revers }\end{array}$ & $\begin{array}{l}\text { I associate this brand with things that are from Iran } \\
\text { For me, this brand does not represent what Iran is (R) } \\
\text { For me, this is a good symbol of Iran } \\
\text { uestion }\end{array}$ & Steenkamp et al. (2003) & $\begin{array}{r}\text { Table } 3 . \\
\text { Constructs and } \\
\text { measures }\end{array}$ \\
\hline
\end{tabular}

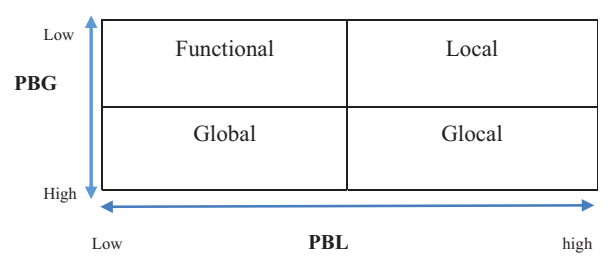

Source: Llonch-Andreu et al. (2016);

Steenkamp and De Jong, (2010)
Figure 1.

Consumer-based brand categorization

\section{Results}

\subsection{Consumer-based brand categorization}

The consumer-based categorized brands were calculated from median values for the PBG and PBL constructs of the 28 brands. In the methodology proposed by Llonch-Andreu et al. (2016), the results obtained from median, mean and mode were practically equal, and thus, we followed the same method with a median. In our study, if the median of both PBG and PBL was moderate in the scale (equal to 4 out of 7 in the seven-point Likert scale), it was considered a "neutral" brand (Table 8).

Of the 28 brands participating in the survey, 13 brands $(46 \%)$ received a different categorization than the objective approach. Surprisingly, all the 13 brands were traditionally local brands from various product categories, and none of them was objectively global. The global brands remained the same in both objective and consumer classifications. Based on the consumer's perception, 15 brands were categorized as global (53.6\%), with 11 of them $(39.3 \%)$ being global and four (14.3\%) being local, four $(14.3 \%)$ as local, eight $(28.6 \%)$ as glocal, and one as neutral (Table 9).

As shown in Table 8, the results indicated that out of 17 objective-based local brands, only four were categorized as local according to the consumer's point of view. In contrast, four were classified as global and eight as glocal, with one being considered neutral. By comparing our results with the previous studies, it was found that some global brands based on objective criteria were perceived as local or glocal by consumers, but it did not occur in this study. The Iranian consumers classified all the global brands in the global category and not in the local or glocal category (Table 10). 
JIMA

14,1

12

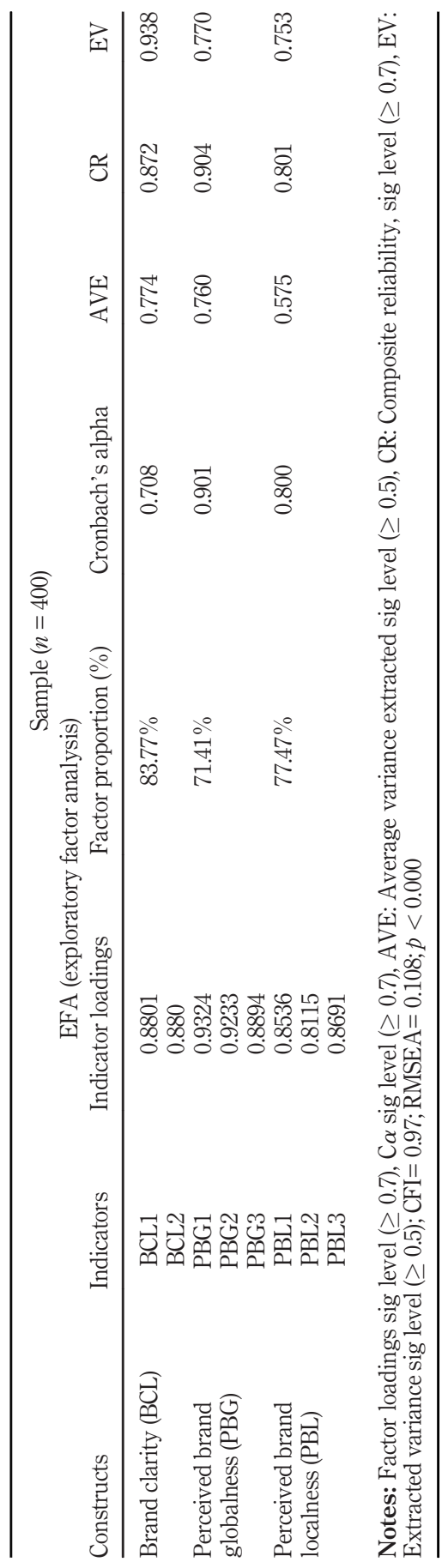

Table 4.

Construct reliability and validity 


\subsection{Test of hypotheses}

To test the first hypothesis and determine whether the mean of the dependent and quantitative variable, BCL, was the same in more than two unrelated and independent groups, types of brands (TOB), we run a one-way ANOVA test. Our dependent variable (BCL) was an interval, and our independent variable (TOB) was categorical; hence, the ANOVA test is a helpful technique for such statistical inference. Additionally, to test the second hypothesis, to assess whether the mean of $\mathrm{BCL}$ was the same in the two unrelated and independent groups of PEB, we run a T-test (Table 11).

Before running ANOVA, first, it is needed to test the data for the homogeneity of variances. We run Bartlett's test for non-normal samples to check the equal variance, and we assumed to accept $H O$ "all input samples are from populations with equal variances." The result of Bartlett's test showed that the variance of the outcome variable, BCL, was equal in all the three groups $\left(\chi^{2}=1.381, p=0.501\right)$ (Table 12).

Next, we developed the ANOVA test, and the result showed that there was a statistically significant difference between the groups, as determined with one-way ANOVA (F [2,

\begin{tabular}{lccccc}
\hline Constructs & MEAN & SD & PBG & PBL & BCL \\
\hline Perceived brand globalness (PBG) & 4.653 & 1.986 & 0.871 & & \\
Perceived brand localness (PBL) & 4.186 & 1.822 & 0.526 & 0.758 & \\
Brand clarity (BCL) & 4.292 & 1.857 & 0.829 & 0.172 & 0.880
\end{tabular}

Notes: Italicized figures on the diagonal show square root of the average variances extracted AVEs; numbers below the diagonal represent the squared inter-construct correlations

Brand clarity of local and global brands

\begin{tabular}{|c|c|c|c|}
\hline Constructs & Brand clarity & Perceived brand globalness & Perceived brand localness \\
\hline
\end{tabular}

Brand clarity

Perceived brand globalness $\quad 0.103$

0.103

0.273

Note: HTMT values are presented under the diagonal and estimate the inter-construct correlations, accepting level $(<0.85)$

Table 6.

Discriminant validity, Heterotrait-

Monotrait ratio

(HTMT)

\begin{tabular}{lcccc}
\hline Constructs & & $\begin{array}{c}\text { Brand } \\
\text { clarity }\end{array}$ & $\begin{array}{c}\text { Perceived brand } \\
\text { globalness }\end{array}$ & $\begin{array}{c}\text { Perceived brand } \\
\text { localness }\end{array}$ \\
\hline Brand clarity & BCL1 & 0.881 & 0.072 & 0.427 \\
(BCL) & BCL2 & 0.880 & 0.080 & 0.352 \\
Perceived brand globalness & PBG1 & 0.074 & 0.932 & 0.185 \\
(PBG) & PBG2 & 0.054 & 0.923 & 0.170 \\
& PBG3 & 0.096 & 0.889 & 0.256 \\
Perceived brand localness (PBL) & PBL1 & 0.326 & 0.305 & 0.853 \\
& PBL2 & 0.337 & 0.158 & 0.811 \\
& PBL3 & 0.447 & 0.145 & 0.869
\end{tabular}

Notes: Italicized figures on the diagonal present the factor loadings of constructs, accepting level $(\geq 0.7)$ or higher factor loading represents that the factor extracts sufficient variance from that variable

Table 7.

Confirmatory factor analysis (CrossLoadings) 
JIMA

14,1

14

$2484]=76.52, p<0.001)$. We also carried out post hoc tests to determine whether there was a statistically significant difference between TOB groups. The Tukey post hoc test output included the mean (contrast) for each group and the relevant two-tailed $p$-value. The results revealed significant differences between the groups, as determined with the one-way ANOVA and Tukey post hoc tests. It was indicated that BCL was significantly higher for local brands than for global ("global vs local" contrast $=-0.942, p<0.001$ ) or glocal brands ("glocal vs local" contrast $=-0.243, p<0.05$ ). Further, BCL was higher for glocal brands than for global brands ("glocal vs global" contrast $=0.698, p<0.001$ ) (Table 12).

According to the result, as we expected, the BCL level was lower in glocal brands than in local ones, and contrary to our expectation, the BCL level was higher in glocal brands than in global. Thus, $H 1$ is partially supported (Table 13 ).

Next, by developing a $t$-test between consumers with and without PEB, this study sought to investigate whether BCL was significantly different in various brands, depending on PEB.

The result showed that the population means were equal for both groups and that there were no significant differences in BCL for different TOB between consumers with and without PEB $(t$-values "BCL by PEB for TOB" $=0.925, p=0.093)$. Additionally, there were no significant differences in the level of $\mathrm{BCL}$ for local and global brands between consumers with and without PEB ("BCL by PEB local brands $=0.147, p=0.882$ ) and ("BCL by PEB global brands $=-0.011$, $p=0.990$ ). The results identified no significant differences in BCL level for glocal brands between consumers with and without $\mathrm{PEB}$, and $\mathrm{H} 2$ is not supported ("BCL by PEB glocal brands = $-1.888, p=0.059)$. However, the $p$-value is almost sig at "0.549" (Tables 13 and 14).

\section{Discussion and conclusions}

This study analyzed the brand-categorization method and brand clarity factor toward enhancing our comprehension of the consumer's perception of brand globalness and localness for types of brand, including local, global and glocal brands. The results of this study provided further insights into brand categorization based on different perspectives,

Table 8.

Consumer-based brand categorization

\begin{tabular}{lll}
\hline PBG (1-2-3-4-5-6-7) & PBL (1-2-3-4-5-6-7) & Brand categorization result \\
\hline High (5-6-7) & Low(1-2-3) or Neutral (4) & Global \\
Low (1-2-3) or neutral (4) & High (5-6-7) & Local \\
High (5-6-7) & High (5-6-7) & Glocal \\
Neutral (4) & Neutral (4) & Neutral
\end{tabular}

Source: Adapted from Llonch-Andreu et al. (2016)

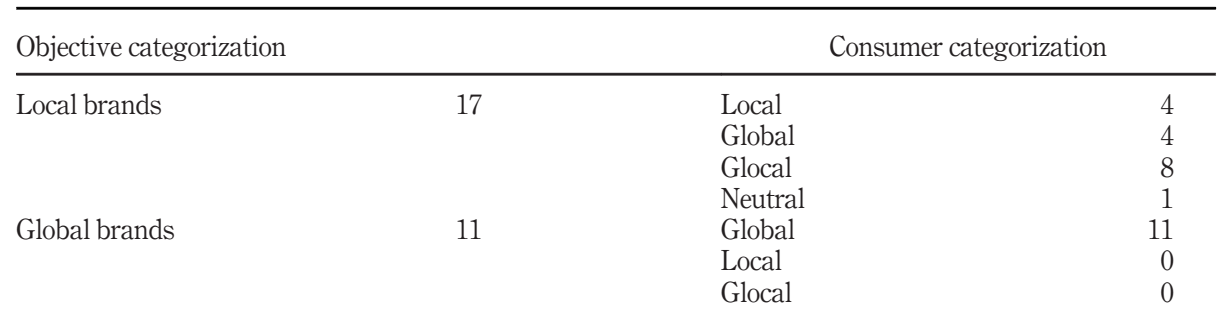

Table 9.

Number of categorized brands 


\begin{tabular}{|c|c|c|c|c|c|c|c|c|c|}
\hline No. & $\begin{array}{l}\text { Product } \\
\text { category }\end{array}$ & Brand name & PBG & PBL & $\begin{array}{l}\text { Median } \\
\text { PBG }\end{array}$ & PBL & $\begin{array}{l}\text { Consumer-based } \\
\text { brand category }\end{array}$ & $\begin{array}{l}\text { Objective-based } \\
\text { brand category }\end{array}$ & of local and \\
\hline 1 & Tea & Twining & 6 & 3 & High & Low & Global & Global & \\
\hline 2 & Hand wash Liquid & Lux & 6 & 4 & High & Neutral & Global & Global & \\
\hline 3 & Dairy Dessert & Dannet & 6 & 3 & High & Low & Global & Global & \\
\hline 4 & Tea & Lipton & 5 & 4 & High & Low & Global & Global & \\
\hline 5 & Toothpaste & Colgate & 5 & 4 & High & Neutral & Global & Global & 15 \\
\hline 6 & Chocolate & Lindt & 5 & 4 & High & Neutral & Global & Global & \\
\hline 7 & Shampoo & Pantene & 6 & 4 & High & Neutral & Global & Global & \\
\hline 8 & Olive Oil & Hojiblanka & 6 & 3 & High & Low & Global & Global & \\
\hline 9 & Toothpaste & Close Up & 6 & 4 & High & Low & Global & Global & \\
\hline 10 & Shampoo & Loreal & 5 & 3 & High & Low & Global & Global & \\
\hline 11 & Hand wash Liquid & Dov & 5 & 3 & High & Low & Global & Global & \\
\hline 12 & Hand wash Liquid & Eco & 5 & 4 & High & Neutral & Global & Local & \\
\hline 13 & Tea & Dogazal & 5 & 3 & High & Low & Global & Local & \\
\hline 14 & Olive Oil & Famila & 5 & 3 & High & Low & Global & Local & \\
\hline 15 & Chocolate & Baraka & 5 & 3 & High & Low & Global & Local & \\
\hline 16 & Shampoo & Sehat & 5 & 5 & High & High & Glocal & Local & \\
\hline 17 & Chocolate & Shirin Asal & 5 & 5 & High & High & Glocal & Local & \\
\hline 18 & Shampoo & Parjak & 5 & 5 & High & High & Glocal & Local & \\
\hline 19 & Dairy Dessert & Kaleh & 6 & 6 & High & High & Glocal & Local & \\
\hline 20 & Tea & Golestan & 6 & 5 & High & High & Glocal & Local & \\
\hline 21 & Hand wash Liquid & Active & 5 & 5 & High & High & Glocal & Local & \\
\hline 22 & Dairy Dessert & Pak & 5 & 5 & High & High & Glocal & Local & \\
\hline 23 & Chocolate & Aydin & 5 & 5 & High & High & Glocal & Local & \\
\hline 24 & Toothpaste & Darougar & 3 & 5 & Low & High & Local & Local & \\
\hline 25 & Olive Oil & Etka & 4 & 5 & Neutral & High & Local & Local & \\
\hline 26 & Toothpaste & Pooneh & 3 & 5 & Low & High & Local & Local & \\
\hline 27 & Dairy Dessert & Mimas & 3 & 5 & Low & High & Local & Local & \\
\hline 28 & Olive Oil & Oila & 4 & 4 & Neutral & Neutral & Neutral & Local & $\begin{array}{r}\text { Table 10. } \\
\text { Brand categorization }\end{array}$ \\
\hline \multicolumn{9}{|c|}{ Notes: PBG: perceived brand globalness, PBL: perceived brand localness } & results \\
\hline
\end{tabular}

\begin{tabular}{|c|c|c|c|c|c|}
\hline Hypotheses & $\begin{array}{c}\text { Independent, } \\
\text { qualitative, and } \\
\text { categorical variable }\end{array}$ & $\begin{array}{c}\text { Dependent, } \\
\text { quantitative and } \\
\text { interval variable }\end{array}$ & Statistical method & Prob. distribution & \\
\hline$H 1$ & $\begin{array}{l}\text { TOB: More than } 2 \\
\text { groups (local, global, } \\
\text { glocal) }\end{array}$ & $\mathrm{BCL}$ & $\begin{array}{l}\text { Analysis of } \\
\text { variance (one-way } \\
\text { ANOVA) }\end{array}$ & $\mathrm{F}$ distribution & \multirow{3}{*}{$\begin{array}{r}\text { Table 11. } \\
\text { Statistical methods } \\
\text { used to test } \\
\text { hypotheses }\end{array}$} \\
\hline$H 2$ & PEB: 2 groups (yes, no) & $\mathrm{BCL}$ & T-test & $\mathrm{T}$ distribution & \\
\hline \multicolumn{5}{|c|}{ Notes: TOB: type of brands, PEB: previous experience with the brand, BCL: brand clarity } & \\
\hline
\end{tabular}

not only from an objective view but also from the consumer's point of view (Llonch-Andreu et al., 2016).

\subsection{Theoretical contribution}

Theoretically, the results developed the consumer-based brand categorization concept (Llonch-Andreu et al., 2016) and subjective types of brands (Koubaa et al., 2015). The idea of 
JIMA

14,1

16

consumer-based brand categorization contributes to enhancing the values of brand types (local, global and glocal), which is substantial for both academics and marketers. Our study confirmed a balanced understanding between objective and consumer-based brand categorization based on PBG and PBL (Llonch-Andreu et al., 2016) for FMCGs.

Comparing the results with the previous studies showed that consumers perceived local brands differently from an objective criterion in the present study, which did not occur in global ones. For example, the consumers classified all the 11 global brands (objective category) in the same global brands. While out of the 17 local brands (objective category), eight were categorized as glocal brands and four as global brands (subjective category). However, only four of the brands were classified as local, which was the same in the objective and subjective categories. According to our findings, local brands with the high median in PBG and PBL were categorized as glocal brands, whereas local brands with the high median in PBG and low median in PBL were classified as global brands. The key

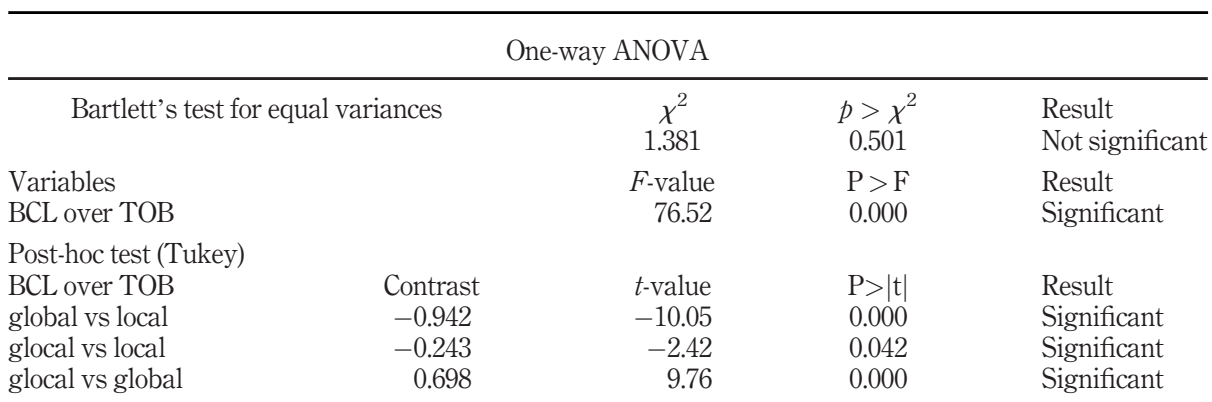

Table 12.

Output reports for Brand clarity (BCL) over types of brands (TOB)

Note: Bartlett's test for equal variances, $p$-value $>0.05 \rightarrow \operatorname{accept} H O$.

\begin{tabular}{lccl}
\hline & \multicolumn{2}{c}{ Whole type of brands (TOB) } & \\
\hline T-test & & $\mathrm{P}>|\mathrm{t}|$ & \\
Variables & $t$-value & 0.093 & Result \\
BCL by PEB & 0.925 & & Not significant \\
Sort type of brands (TOB) & & $\mathrm{P}>|\mathrm{t}|$ & \\
T-test & & 0.882 & Result \\
BCL by PEB & $t$-value & 0.990 & Not significant \\
Local brands & 0.147 & 0.059 & Not significant \\
Global brands & -0.011 & & Not significant \\
Glocal brands & -1.888 &
\end{tabular}

\section{Table 13.}

Output reports for brand clarity $(\mathrm{BC})$ by previous experience with the brand (PEB)

brand

$-1.888$

Hypothesis

Conclusion

Table 14.

H2. The BCL level is lower in glocal brands than in local or global brands hypotheses among consumers with no prior experience

Partially supported Not supported 
reasons behind the consumer's different perception of brand classification might be the brand's higher perceived quality, the company's standardization of brand positioning or the consumer's various personal associations with the brands (Holt, 2002; Strizhakova et al., 2008; Koubaa et al., 2015; Llonch-Andreu et al., 2016). However, there is a need to perform more investigation to determine the main reasons behind the consumer's different perceptions in local/global brand categorization.

Moreover, this study enriched understanding of the consumer's perception of brand clarity in the signaling theory (Erdem and Swait, 1998). The present study analyzed the data from the survey of Iranian consumers, and the results showed a significant difference in $\mathrm{BCL}$ between the different types of brands. The findings revealed that BCL was lower in glocal brands than in global brands (H1), while it was higher in local brands. Instead, BCL was more elevated in local brands than in global or glocal brands. Hence, as expected, local brands had more brand clarity than glocal brands, and contrary to our expectations, glocal brands had more brand clarity than global brands. This result may support the fact that local brands send signals that are more precise to consumers than global and glocal ones due to their higher PBL, local brand name, clear symbols or heightened brand awareness in local icons (Özsomer, 2012). Further, glocal brands had more brand clarity than global brands because these brands originally were local (objective category), and thus, the consumers received clear local signals from them.

It was also shown that the consumer's perception of a brand in a Muslim country such as Iran was likely different from that in a non-Muslim country, and a global standard strategy may not be effective; thus, Iran's consumer market can be unpredictable (Mirkhah and Karami, 2019). The findings of this study showed that local brands might have more clarity than global brands for FMCGs among consumers from a developing country like Iran. One of the reasons can be the impact of economic restrictions and business limitations in the global market.

Furthermore, contrary to our expectations, the findings of this study showed that there was no significant difference in BCL between consumers with and without PEB. In the current study, PEB had no impact on BCL for local, global and glocal brands, but it may affect the brand credibility level. Thus, future research could investigate the influence of prior experience on brand clarity and brand credibility (Erdem and Swait, 1998, 2004; Erdem et al., 2006).

\subsection{Managerial implications}

Our research has several practical implications for firms who market their brands globally and domestically in Muslim countries. It provides insights into how companies should reposition their FMCG brands in an emerging market while considering relevant local and global brands. Marketing managers need to realize that both globally and locally perceived brands are appreciated not only for their quality (Xie et al., 2015) and for their ability to create a clear signal to facilitate consumer's perception process and their willingness to purchase.

It is recommended for global and local brand managers to analyze brand categorization from the consumer's perspective instead of relying only on objective categorization such as the published brand databases. Moreover, brand owners would be able to discover the real positioning of their brands and that of their competitor's brands in domestic and international markets.

By comparing the findings in Iran with those of a previous study conducted in the emerging economy of Mexico (Llonch-Andreu et al., 2016), it was found that Mexican consumers perceived some brands categorized as global based on objective criteria as local 
or glocal. This discrepancy between the objective criteria and the consumer's perception was not observed in Iran.

Moreover, delivering clear signals of localness and globalness for consumers makes marketing mix solidity create long-term committed customer relationships, especially in FMCG brands.

Local brand managers can improve their marketing mix elements to clarify local perception to increase perceived quality and purchase intention for local brands in domestic markets. According to Mirkhah and Karami (2019), when Western brands plan to target local consumers, they should focus less on Western attributes. Thus, it might be necessary for global brand managers to know that local brands have more brand clarity than global and glocal brands. If international companies with FMCG global brands are interested in entering and being competitive in restricted domestic markets, adapting global brands to glocal positioning appears to be a good strategy. It will increase BCL and ultimately help consumers perceive brands with clear local signals. Thus, global brand managers can adapt their brand positioning based on the local icons for global brands.

\section{Limitations and future directions}

To generalize the outcomes of this study, future research could look into extending the study population with an additional survey with a different number of brands and categories (Özsomer, 2012) for durable products in more developed and developing countries. Another limitation was using a sample of consumers from Tehran, Iran, and not from other cities.

A further study focusing on halal brands and halal- decision-making patterns in consumer behavior for brand engagements (Wilson and Liu, 2011) is suggested.

Several questions remain unanswered at present; thus, it is suggested to perform more comprehensive studies to explore the impact of consumer attitudinal disposition and consumer psychological behavior on brand categorization and purchase intention in another Muslim market. Our research would have been more interesting if it had included more variables as signal criteria. Therefore, an additional survey based on the signaling theory is also suggested to analyze types of brands, brand credibility, perceived risk and value creation (Erdem and Swait, 1998; Erdem et al., 2006; Erdem et al., 2006; Lopez-Lomelí et al., 2019).

It is also recommended to conduct a qualitative or an experimental study to manipulate promotional activities (Heinberg et al., 2017). Empirically testing the causal relationship among different local/global drivers through the company's strategy and the consumer's perception in a large-scale study would further validate the concept.

\section{References}

Aaker, J., Fournier, S. and Brasel, S.A. (2004), "When good brands do bad", Journal of Consumer Research, Vol. 31 No. 1, pp. 1-16.

Alden, D.L., Steenkamp, J.-B.E.M. and Batra, R. (2006), "Consumer attitudes toward marketplace globalization: structure, antecedents, and consequences", International Journal of Research in Marketing, Vol. 23 No. 3, pp. 227-239.

Baker, M., Sterenberg, G. and Taylor, E. (2007), "Managing global brands to meet consumer expectations", Market Research Best Practices, Chichester, John Wiley and Sons Ltd, pp. 443-466.

Batra, R., Ramaswamy, V., Alden, D.L., Steenkamp, J.B.E. and Ramachander, S. (2000), "Effects of brand local and nonlocal origin on consumer attitudes in developing countries", Journal of Consumer Psychology, Vol. 9 No. 2, pp. 83-95. 
Cavusgil, S.T., Deligonul, S., Kardes, I. and Cavusgil, E. (2018), "Middle-class consumers in emerging markets: conceptualization, propositions, and implications for international marketers", Journal of International Marketing, Vol. 26 No. 3, pp. 94-108.

Chailan, C. and Ille, F. (2015), "Branding from emerging countries: how to compete internationally", Critical Perspectives on International Business, Vol. 11 No. 1, pp. 54-71.

Chinomona, R. (2013), "The influence of brand experience on brand satisfaction, trust and attachment in South Africa", International Business and Economics Research Journal (Iber), Vol. 12 No. 10, pp. 1303-1316.

Brand clarity of local and global brands

Churchill, G.A. Jr, (1979), “A paradigm for developing better measures of marketing constructs”, Journal of Marketing Research, Vol. 16 No. 1, pp. 64-73.

City mayors (2017), "The largest cities in the world by land area, population and density", available at: www.citymayors.com/statistics/largest-cities-density-125.html

Davis, S. and Rao, A.R. (1991), "Signaling product quality to and through a retailer", Unpublished manuscript, School of Business, Washington University, St. Louis, MO.

Davvetas, V., Sichtmann, C. and Diamantopoulos, A. (2015), "The impact of perceived brand globalness on consumers' willingness to pay", International Journal of Research in Marketing, Vol. 32 No. 4, pp. 431-434.

Dimofte, C.V., Johansson, J.K. and Ronkainen, I.A. (2008), "Cognitive and affective reactions of US consumers to global brands", Journal of International Marketing, Vol. 16 No. 4, pp. 113-135.

Dumitrescu, L. and Vinerean, S. (2010), "The glocal strategy of global brands", Studies in Business and Economics, Vol. 5 No. 3, pp. 147-155.

Erdem, T. and Swait, J. (1998), "Brand equity as a signaling phenomenon", Journal of Consumer Psychology, Vol. 7 No. 2, pp. 131-157.

Erdem, T. and Swait, J. (2004), "Brand credibility, brand consideration, and choice", Journal of Consumer Research, Vol. 31 No. 1, pp. 191-198.

Erdem, T., Swait, J. and Valenzuela, A. (2006), "Brands as signals: a cross-country validation study", Journal of Marketing, Vol. 70 No. 1, pp. 34-49.

Floren, J., Rasul, T. and Gani, A. (2019), "Islamic marketing and consumer behavior: a systematic literature review", Journal of Islamic Marketing, Vol. 11 No. 6, pp. 1557-1578.

Fornell, C. and Larcker, D.F. (1981), "Structural equation models with unobservable variables and measurement error: Algebra and statistics".

Giulianotti, R. and Robertson, R. (2012), Glocalization, The Wiley-Blackwell Encyclopedia of Globalization.

Godey, B. and Lai, C. (2011), "Construction of international brand portfolios: impact on local brands", Journal of Product and Brand Management.

Halkias, G., Davvetas, V. and Diamantopoulos, A. (2016), "The interplay between country stereotypes and perceived brand globalness/localness as drivers of brand preference", Journal of Business Research, Vol. 69 No. 9, pp. 3621-3628.

Hanna, N. and Wozniak, R. (2013), “Consumer perception”, Consumer Behavior: An Applied Approach, Kendall Hunt Publishing, Dubuque, pp. 73-108.

He, J. and Wang, C.L. (2017), "How global brands incorporating local cultural elements increase consumer purchase likelihood: an empirical study in China", International Marketing Review, Vol. 34 No. 4, pp. 463-479.

Heinberg, M., Ozkaya, H.E. and Taube, M. (2017), "The influence of global and local iconic brand positioning on advertising persuasion in an emerging market setting", Journal of International Business Studies, Vol. 48 No. 8, pp. 1009-1022.

Henseler, J., Ringle, C.M. and Sarstedt, M. (2015), "A new criterion for assessing discriminant validity in variance-based structural equation modeling", Journal of the Academy of Marketing Science, Vol. 43 No. 1, pp. 115-135. 
Holt, D.B. (2002), "Why do brands cause trouble? A dialectical theory of consumer culture and branding", Journal of Consumer Research, Vol. 29 No. 1, pp. 70-90.

Interbrand (2016), "Best global brands 2016 rankings", available at: http://interbrand.com/best-brands/ best-global-brands/2016/ranking/

Izberk-Bilgin, E. and Nakata, C.C. (2016), "A new look at faith-based marketing: the global halal market”, Business Horizons, Vol. 59 No. 3, pp. 285-292.

Kapferer, J.N. (2002), “Is there really no hope for local brands?”, Journal of Brand Management, Vol. 9 No. 3, pp. 163-170.

Keller, K.L. and Lehmann, D.R. (2006), "Brands and branding: research findings and future priorities", Marketing Science, Vol. 25 No. 6, pp. 740-759.

Kervyn, N., Fiske, S.T. and Malone, C. (2012), "Brands as intentional agents framework: how perceived intentions and ability can map Brand perception”, Journal of Consumer Psychology, Vol. 22 No. 2, pp. 166-176.

Khondker, H.H. (2004), "Glocalization as globalization: evolution of a sociological concept”, Bangladesh e-Journal of Sociology, Vol. 1 No. 2, pp. 1-9.

Kirmani, A. (1990), "The effect of perceived advertising cost on brand perceptions", Journal of Consumer Research, Vol. 17 No. 2, pp. 160-171.

Kotabe, M. and Helsen, K. (2000), Global Marketing Administration, So Paulo, Atlas.

Kotler, P., et al. (2009), Marketing Management - European Edition, Harlow, England, Pearson”, Prentice Hall Publishing, pp. 467 - 468.

Koubaa, Y., Methamem, R.B. and Fort, F. (2015), "Multidimensional structures of brand and country images, and their effects on product evaluation", International Journal of Market Research, Vol. 57 No. 1, pp. 95-124.

Krejcie, R.V. and Morgan, D.W. (1970), "Determining sample size for research activities", Educational and Psychological Measurement, Vol. 30 No. 3, pp. 607-610.

Kushwah, S., Shree, D., Rezaei, S. and Sagar, M. (2019), "The impact of culture on consumer's perception of brand identity: evidences from Gulf countries", Journal of Islamic Marketing, Vol. 11 No. 2, publication date: 18 May 2019.

Lavrakas, P.J. (2008), Encyclopedia of Survey Research Methods, Sage publications.

Llonch-Andreu, J., López-Lomelí, M.A. and Gómez-Villanueva, J.E. (2016), "How local/global is your brand? A technique to assess brand categorization", International Journal of Market Research, Vol. 58 No. 6, pp. 795-813.

Lopez-Lomelí, M.Á., Llonch-Andreu, J. and Rialp-Criado, J. (2019), "Local, global and glocal consumer brand relationships", Spanish Journal of Marketing-ESIC, Vol. 23 No. 3, pp. 437-459.

Mangleburg, T.F., Sirgy, M.J., Grewal, D., Axsom, D., Hatzios, M., Claiborne, C.B. and Bogle, T. (1998), "The moderating effect of prior experience in consumers' use of user-image based versus utilitarian cues in brand attitude", Journal of Business and Psychology, Vol. 13 No. 1, pp. 101-113.

Maynard, M. and Tian, Y. (2004), "Between global and glocal: content analysis of the Chinese web sites of the 100 top global brands", Public Relations Review, Vol. 30 No. 3, pp. 285-291.

Mirkhah, S.M. and Karami, N. (2019), "Investigating the impact of religious commitment on purchase of self-expressive brand products", Journal of Islamic Marketing, Vol. 11 No. 2, pp. 000-000.

Muhamad, N. and Mizerski, D. (2010), "The constructs mediating religions' influence on buyers and consumers", Journal of Islamic Marketing, Vol. 1 No. 2, pp. 124-135.

Murray, C.J., Callender, C.S., Kulikoff, X.R., Srinivasan, V., Abate, D., Abate, K.H., ... Abdelalim, A. (2018), "Population and fertility by age and sex for 195 countries and territories, 1950-2017: a systematic analysis for the global burden of disease study 2017", The Lancet, Vol. 392 No. 10159, pp. 1995-2051. 
Neyman, J. (1992), "On the two different aspects of the representative method: the method of stratified sampling and the method of purposive selection", Breakthroughs in Statistics, Springer, New York, NY, pp. 123-150.

Nunnally, J.C. and Bernstein, I.H. (1994), Validity. Psychometric Theory, New York, NY, McGraw-Hill, Vol. 3, pp. 99-132.

Ogilvy Noor (2010), "Brands and Muslim consumers", Keynote address by Miles Young, CEO, Ogilvy and Mather Worldwide, Oxford Global Islamic Branding and Marketing Forum, 26-27 July, Sa1«d Business School, University of Oxford, Oxford.

Ozer, S. (2019), "Towards a psychology of cultural globalisation: a sense of self in a changing world", Psychology and Developing Societies, Vol. 31 No. 1, pp. 162-186.

Özsomer, A. (2012), "The interplay between global and local brands: a closer look at perceived brand globalness and local iconness", Journal of International Marketing, Vol. 20 No. 2, pp. 72-95.

Özsomer, A. and Altaras, S. (2008), "Global brand purchase likelihood: a critical synthesis and an integrated conceptual framework", Journal of International Marketing, Vol. 16 No. 4, pp. $1-28$.

Peter, J.P., Olson, J.C. and Grunert, K.G. (1999), Consumer Behaviour and Marketing Strategy, London, McGraw-hill.

Peter, J.P., Olson, J.C. and Grunert, K.G. (1999), Consumer Behaviour and Marketing Strategy, McGrawHill, London.

Potrafke, N. (2015), “The evidence on globalisation”, The World Economy, Vol. 38 No. 3, pp. 509-552.

Robertson, R. (1992), Globalization: Social Theory and Global Culture, Sage, Vol. 16.

Schuiling, I. and Kapferer, J.N. (2004), "Executive insights: real differences between local and international brands: strategic implications for international marketers", Journal of International Marketing, Vol. 12 No. 4, pp. 97-112.

Sekaran, U. (1983), "Methodological and theoretical issues and advancements in cross-cultural research", Journal of International Business Studies, Vol. 14 No. 2, pp. 61-73.

Sichtmann, C., Davvetas, V. and Diamantopoulos, A. (2019), "The relational value of perceived brand globalness and localness", Journal of Business Research, Vol. 104, pp. 597-613.

Statistical Center of Iran (2016), "Selected results of national population and housing census", available at: www.amar.org.ir/english

Steenkamp, J.B. (2017), “Global Brand equity”, Global Brand Strategy, Palgrave Macmillan, UK.

Steenkamp, J.-B. (2019), "The uncertain future of globalization: implications for global consumer culture and global brands", International Marketing Review, Vol. 36 No. 4, pp. 524-535.

Steenkamp, J.B.E. and de Jong, M.G. (2010), "A global investigation into the constellation of consumer attitudes toward global and local products", Journal of Marketing, Vol. 74 No. 6, pp. 18-40.

Steenkamp, J.B.E., Batra, R. and Alden, D.L. (2003), "How perceived brand globalness creates brand value", Journal of International Business Studies, Vol. 34 No. 1, pp. 53-65.

Strizhakova, Y., Coulter, R.A. and Price, L.L. (2008), "The meanings of branded products: a crossnational scale development and meaning assessment ", International Journal of Research in Marketing, Vol. 25 No. 2, pp. 82-93.

Svensson, G. (2001), “Glocalization” of business activities: a 'glocal strategy' approach”, Management Decision, Vol. 39 No. 1, pp. 6-18.

Tehran Population (2019), “World population review”, available at: http://worldpopulationreview.com/ world-cities/tehran-population/

Thomson Reuters (2016), Report: State of the Global Islamic Economy 2016/17, Thomson Reuters, New York, NY. 
JIMA

14,1

Thomson, M., MacInnis, D.J. and Whan Park, C. (2005), "The ties that bind: measuring the strength of consumers' emotional attachments to brands”, Journal of Consumer Psychology, Vol. 15 No. 1, pp. $77-91$.

Veloutsou, C. (2008), "Branding: a constantly developing concept", Journal of Brand Management, Vol. 15 No. 5, pp. 299-300.

Vera, J. and Trujillo, A. (2017), "Searching most influential variables to brand loyalty measurements: an exploratory study", Contaduria y Administración, Vol. 62 No. 2, pp. 600-624.

Wilson, J.A. and Liu, J. (2011), "The challenges of Islamic branding: navigating emotions and halal", Journal of Islamic Marketing, Vol. 2 No. 1, pp. 28-42.

Winit, W., Gregory, G., Cleveland, M. and Verlegh, P. (2014), "Global vs local brands: how home country bias and price differences impact Brand evaluations", International Marketing Review, Vol. 31 No. 2, pp. $102-128$.

Wood, W. and Kallgren, C.A. (1988), "Communicator attributes and persuasion: recipients' access to attitude-relevant information in memory", Personality and Social Psychology Bulletin, Vol. 14 No. 1, pp. 172-182.

World Capital Institute (2013), “Tehran, Iran”, available at: www.worldcapitalinstitute.org/ makciplatform/

Xie, Y., Batra, R. and Peng, S. (2015), "An extended model of preference formation between global and local brands: the roles of identity expressiveness, trust, and affect", Journal of International Marketing, Vol. 23 No. 1, pp. 50-71.

Yakup, D.D. and Diyarbakirlioglu, I. (2011), "A theoritical theoretical approach to the role of perception on the consumer buying decision process", Asian Journal of Business and Management Sciences, Vol. 1, pp. 217-221.

\section{Further reading}

Baek, T.H., Kim, J. and Yu, J.H. (2010), "The differential roles of brand credibility and brand prestige in consumer brand choice", Psychology and Marketing, Vol. 27 No. 7, pp. 662-678.

Keller, K.L. (2002), Branding and Brand Equity, Cambridge, MA, Marketing Science Institute.

Schmitt, B. (2012), "The consumer psychology of brands", Journal of Consumer Psychology, Vol. 22 No. 1, pp. 7-17.

Tian, R.G. and Emery, C. (2002), "Cross-cultural issues in internet marketing”, Journal of American Academy of Business, Vol. 1 No. 2, pp. 217-224.

\section{Corresponding author}

Maryam Vaziri can be contacted at: maryam.vaziri@e-campus.uab.cat

For instructions on how to order reprints of this article, please visit our website: 